\title{
THE IMPACT OF SOCIAL NETWORK ON THE INNOVATIVE BEHAVIOR OF IT PROFESSIONALS: WHAT IS THE ROLE OF SHARING MISTAKES?
}

\section{Alireza Khorakian, Mostafa Jahangir}

\section{Introduction}

Innovation is widely considered as an important factor for competitiveness and has been a focus of research for decades (Szabo, Soltés, \& Herman, 2013). Innovation is very important for organizations and companies, because it helps them to gain a constant competitive advantage in today's uncertain environment; and they can dominate their rivals (Teigland, Di Gangi, Flåten, Giovacchini, \& Pastorino, 2014). Organization have to innovate in order to survive (Bowers \& Khorakian, 2014). Because of rapid changes and intense competition in IT industry, IT companies need more innovation to grow and survive. Those companies who cannot present innovative products and services to the market constantly will definitely lose (Constantinides, 2013). One can refer to such kinds of companies as AOL, WebTV, Napser, Alta Vista, Nokia, Fairchild and Palm Computing (Bouman, 2010).

Improving the innovative performance of the companies is possible through human resources. Companies which can invest on their human resources can reach innovation; since creative and innovative employees are the creating factors of innovation. But innovation can be created by employees who have innovative behavior, with three dimensions: idea generation, promotion, and implementation (Wang, Fang, Qureshi, \& Janssen, 2015), since the realization of an innovation is in need of idea formation. Then that idea is accepted in the organization and, finally, the accepted idea is implemented (Janssen, 2004). Although some IT companies invest a lot on creating innovation, they seeks for innovation key outside their companies, and as a result they do not reach their expected results, while innovation can be generated from inside the company and among the staff who have innovative behavior.
According to previous researches, various factors affect staff's innovative behavior; one of these factors, is social network among employees. Staff who create social network between each other, have more friendly relationship; they meet outside the company, they know about each other's lives and help each other in their problems. However, a social network is able to improve innovative behavior when this friendly network leads to employees' interest in sharing their work mistakes. Because in order to improve employees' innovative behavior and company's innovative performance, encouraging the employees to share their work mistakes has been considered as one of the major factors (Radaelli, Mura, Spiller, \& Lettieri, 2011). As IT companies' activities are professional and based on knowledge; the importance of sharing work mistakes is very high in improving innovative performance of the companies, since if the employees share their mistakes in their works with each other with peace of mind and willingly, they can propose innovative ideas out of the lessons, learnt from these mistakes to prevent their reoccurrence; this way, besides drawing the managers' approval, they can implement those ideas as well (Mura, Lettieri, Radaelli, \& Spiller, 2013).

Based on what has been mentioned before, it can be said that social network can improve innovative behavior of IT professionals. In this social network, employees will share the mistakes which they have done in their work willingly. In this way they can give innovative ideas in order to avoid redoing these mistakes. In addition, they attract the help of the other members of the company and run these ideas. So, the major question in this research is to what extent social network can affect the innovative behavior of IT professionals while considering the mediatory role of sharing work mistakes. 


\section{Literature Review and Hypothesis Development}

\subsection{Innovative Behavior}

Innovation is the challenging issue for the companies who want to stay competitive (Palmer, 2010) because it is a criteria for differentiating companies and succeeding in a competition. Moreover, a company who can have and implement new ideas, not only accepts change but also can act as a factor in creating change in its environment (Taştan, 2013). Because of rapid change and intense competition in IT industry, active companies in this field need more innovation in order to grow and survive. The major entrances to innovation are knowledge, expertise and staff commitment (Montes, Moreno, \& Fernández, 2004). So to create innovation, IT companies should affect their human resources in order to be able to use their expertise and commitment for creating and developing new ideas. Therefore, IT companies' strategy should be involving people in the process of innovation (Kanter \& Myers, 1996). Innovative behavior is about employees finding, suggesting and implementing new and beneficial work-related ideas (De Spiegelaere, Van Gyes, De Witte, Niesen, \& Van Hootegem, 2014). In another definition, employee innovative behavior has three fields of generating, promoting and implementing an idea. This behavior starts with identifying the problem and presenting new and acceptable ideas and solution (generating idea). In the next stage, the person seeks some supporter to run his idea (promoting idea). And in this way, the idea is either implemented or abandoned because of being impossible (Scott \& Bruce, 1994).

According to the last definition as a selected definition, generating idea deals with idea making and implementing. An employee who creates new ideas has innovative behavior in generating idea aspect; this person always looks for new and innovative methods, techniques, and tools, and he will find creative solutions for work problems. Promoting the idea points at the efforts of a person for attracting managers' support in running new ideas. An employee who tries to have the support of managers in running his new idea has innovative behavior in the aspect of generating the idea; he tries to gain the support and attention of important organization's member. Implementing idea is a more practical effort for changing new ideas to practical Solution and performing them in the work activities of the organization. An employee, who not only presents innovative ideas to his workplace systematically, but also evaluates their benefits and uses and try to implement them, has innovative behavior in the aspect of implementing ideas (Mura et al., 2013).

\subsection{Social Network}

Innovative behavior of IT professionals has been affected by various factors. One of these factors is the existence of social network among the employees. Based on the previous studies, the social network has significant effects on sharing knowledge (Tortoriello, Reagans, \& McEvily, 2012) and innovation (Burt, 2004). Employees who have social network among themselves and have friendly relationship in a way that they see each other outside work, and they are so close that they talk about their personal lives, they help each other in their problems, and in achieving work success they celebrate this progress. The social network can help interpersonal trust (Nonaka, 1994), emotional attachment and continuity of communications (Reagans \& McEvily, 2003) and facilitating information transfer (Wong \& Boh, 2010). But social network will be created in a social environment. Social environment points at social relations between people. The concept of social environment is essentially different from organizational culture. Because organizational culture points at formal behavioral patterns which are dictated by the organization; while social environment points at the fact that how the employees understand their relationships (Borges, 2012).

\subsection{Sharing Mistakes}

One of the other factors which affects the innovative behavior of IT professionals is their willingness to share their knowledge and experiences. But according to this view (Mura et al., 2013), sharing knowledge and experience would not be realized only through sharing the best practice, but it would be realized through sharing mistakes as well. Sharing the best practice and sharing mistakes are different behaviors which are evoked by different conditions; and they provide various benefits and advantages for those who gain the knowledge. Work mistakes have two completely different aspects. On one hand, 
they lead to disadvantages such as losing time, producing defective products and accidents; on the other hand, they have positive results such as innovation and learning (Homsma, Van Dyck, De Gilder, Koopman, \& Elfring, 2009). Also smart learning from mistakes is one of the important properties of innovative company (Cannon \& Edmondson, 2001). An employee has the behavior of sharing mistakes would also share his daily work mistakes and errors through informal interactions and communications; he shares his experiences from these mistakes in his formal meetings with his coworkers; and he has no problem with sharing his mistakes with his colleagues.

\subsection{Social Network and Sharing Mistakes}

The existence of social network is a major factor in sharing mistakes among the staff. Therefore, friendly social network of staff with each other will affect their decisions on sharing their mistakes. Those employees who are not in contact in a social network, are unwilling to share their mistakes; while staff with good relations, will share knowledge, experience and work mistakes, voluntarily and more willing (Small \& Sage, 2006). Hansen, Mors, and Løvås (2005) argue that existence of a strong social network will affect their willingness to share knowledge, experiences and mistakes. Chen and Chen (2009), in a research investigated the factors which affected sharing knowledge, experiences and mistakes from behavioral perspective among MBA students in a virtual education society. They understood that when the members of virtual education society contact with each other, they have a better feeling about sharing ideas, thoughts and experiences. So, it is expected that IT professionals who have strong social relations would share their work mistakes. Because, these people in comparison with those who do not have social relations are more convenient in sharing their mistakes and feel less threats. Therefore, the below hypothesis is mentioned:

H1: Social network has significant and positive impact on sharing mistakes.

\subsection{Sharing Mistakes and Innovative Behavior}

Encouraging sharing mistakes among IT professionals can be counted as one of the important factors in improving innovative behavior (Radaelli et al., 2011). Mura et al. (2013) believe that sharing the best practices and mistakes evoke innovation. As the activities of IT companies are professional, knowledgebased and technology-based; shared mistakes by the employees of these companies has a major role in the innovative performance of these companies. Because work mistake lead to innovative ideas in the minds of IT professionals in order to avoid these mistakes. So for companies it is recommended to encourage and strengthen sharing mistakes behavior in order to transfer the knowledge of IT professionals to innovation and improve the performance of the company. Because sharing mistakes result in generating, promoting and implementing new ideas to avoid remaking these mistakes (Mura et al., 2013). Therefore the below hypotheses are stated:

H2: Sharing mistakes has a significant and positive impact on generating ideas.

H3: Sharing mistakes has a significant and positive impact on promoting ideas.

H4: Sharing mistakes has a significant and positive impact on implementing ideas.

\subsection{Social Network and Innovative Behavior}

Over the past two decades, scholars have increasingly emphasized that the relationships individuals cultivate and the positions they occupy in their social networks hold some of the keys to unleashing their innovative potential (Brass, 2003). There has been burgeoning interest in identifying the features of individuals' social networks that are most powerful in boosting individual innovation in organizations (Phelps, Heidl, \& Wadhwa, 2012). The success of innovative behavior largely depends on an employee's network of relationships within the organization, because it is these relationships that provide the requisite inspiration, information, resources, and support that help innovators develop, promote, and realize their new ideas (Perry-Smith \& Shalley, 2003). Employees are simultaneously embedded in their workgroups and their organization, so their relationships in the organization can be divided into connections within versus outside the workgroup. Prior research has outlined the importance of outside connections in facilitating innovation (Hülsheger, Anderson, \& Salgado, 2009). Social network can be mentioned as a major factor in improving innovative behavior. 
Because in the close and friendly atmosphere of social network, employees are motivated to state their ideas during their friendly dialogues and raise their ideas. So the below hypotheses are stated:

H5: Social network has a significant and positive impact on generating ideas.

H6: Social network has a significant and positive impact on promoting ideas.

H7: Social network has a significant and positive impact on implementing ideas.

\subsection{Mediating Role of Sharing Mistakes in Effect of Social Network on Innovative Behavior}

The presence of a social network among IT professionals would improve their innovative behavior when it can lead to the willingness of the staff in sharing work mistakes in this social network. In other words, it is in a friendly and close atmosphere of a social network that employees would willingly and easily share their work mistakes with each other. As a result, in order to avoid these mistakes, they can create innovative ideas based on their experiences. They can also attract the cooperation of company members and implement these ideas. Therefore, the below hypotheses are stated:

H8: Sharing mistakes has a mediatory role in the impact of social network on generating ideas.
H9: Sharing mistakes has a mediatory role in the impact of social network on promoting ideas.

H10: Sharing mistakes has a mediatory role in the impact of social network on implementing ideas.

\subsection{Research Model}

According to the above mentioned hypotheses, theoretical model of research has been shown in Fig. 1. Research theoretical model shows the impact of the social network on the aspects of innovative behavior with the mediatory role of sharing mistakes.

\section{Methodology}

\subsection{Research Instruments}

In this study, in order to gather required data a questionnaire has been used. The questionnaire of this research has 18 items, and the participant is asked to clarify the amount of his agreement in a five-item Likert scale; number 5 means agree completely and 1 means disagree completely. In order to measure different dimensions of innovative behavior in this study, three dimensions: idea generation, idea promotion and idea implementation have been considered. These dimensions have 9 items and have been derived from Janssen (2000). Sharing mistakes is measured by 4 items

\section{Fig. 1: Research theoretical model}

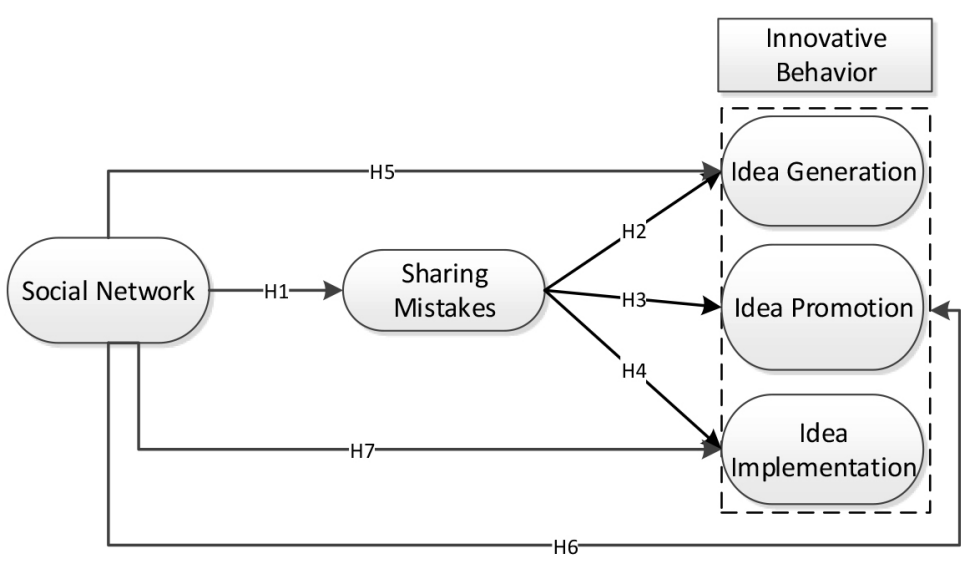


that are derived from Mura et al. (2013). In order to evaluate social network, 5 items have been used which are derived from Borges (2012).

\subsection{Data Collection}

Statistical population of this research are the IT professionals in IT companies who are members of Khorasan Razavi trade organization of computer in Mashhad. According to the list made by Khorasan Razavi ICT Guild Organization in Khordad 1393, the number of this organization's active companies in Mashhad is 156 and total employees of these Companies are 468 , thus the number of this statistical population is almost 468 . The sample size is estimated as 211, using Cochran Formula, with 95\% confidence coefficient and 0.05 tolerable error. In this research, the stratified random sampling was used. 245 questionnaires were distributed among all the IT experts in the selected companies. Finally, this research was conducted on 210 questionnaires.

\subsection{Reliability and Validity of Research Instrument}

In this study, to determine the questionnaire validity, formal validity and construct validity have been used. To investigate formal validity, in research questionnaires, the questions have been determined based on reliable previous studies. And each item has been referred to its reference. Also some experts have been asked to give their opinions upon the validity of the questionnaire. After investigating and evaluating the questionnaire, applying small modifications, and considering experts' opinion, the questionnaire formal validity and its accordance with social norms and research goals has been approved. Also after gathering data, construct validity which includes divergent validity, convergent validity and factor analysis has been investigated and its results will be discussed in results section. In order to measure reliability in the research, in addition to Cronbach's Alpha, combined reliability has been calculated as well, and its results will be shown in result section.

\subsection{Data Analysis Methods}

To test the hypotheses and model fitness, Structural Equation Modeling (ESM) and Partial Least Squares (PLS) have been used. To analyze the data, two-level approach which was suggested by Hulland (1999) has been used, and according to it, one model of structural equations which needs PLS to be solved should

\section{Tab. 1: The demographic features of statistical population}

\begin{tabular}{c|c|c|c} 
Variable & Amounts & Frequency & Frequency Rate \\
\hline \multirow{4}{*}{ Gender } & unanswered & 3 & 1.4 \\
\cline { 2 - 4 } & female & 66 & 31.4 \\
\cline { 2 - 4 } & male & 141 & 67.2 \\
\cline { 2 - 4 } Work & sum & 210 & 100 \\
\cline { 2 - 4 } & unanswered & 13 & 6.2 \\
\cline { 2 - 4 } & 1 to 9 years of age & 175 & 83.4 \\
\cline { 2 - 4 } & 10 to 30 years of age & 22 & 10.4 \\
\cline { 2 - 4 } & sum & 9 & 100 \\
\cline { 2 - 4 } & unanswered & 39 & 4.3 \\
\cline { 2 - 4 } & social networks & 37 & 18.6 \\
\cline { 2 - 4 } & website designing & 35 & 27.2 \\
\cline { 2 - 4 } & programming & 33 & 16.7 \\
\cline { 2 - 4 } & graphic & 210 & 15.7 \\
\cline { 2 - 4 } & hardware & & 100 \\
\hline
\end{tabular}


Tab. 2: The results of confirmatory factor analysis and load factor value for indicators

\begin{tabular}{c|c|c|c|c|c|c} 
Indicators & $\begin{array}{c}\text { Social } \\
\text { Network }\end{array}$ & $\begin{array}{c}\text { Sharing } \\
\text { Mistakes }\end{array}$ & $\begin{array}{c}\text { Idea } \\
\text { Generation }\end{array}$ & $\begin{array}{c}\text { Idea } \\
\text { Promotion }\end{array}$ & $\begin{array}{c}\text { Implemen- } \\
\text { ting Ideas }\end{array}$ & P-values \\
\hline SN1 & 0.921 & 0.389824 & 0.348781 & 0.270926 & 0.223166 & $<0.05$ \\
\hline SN2 & 0.904 & 0.255954 & 0.220001 & 0.163460 & 0.207233 & $<0.05$ \\
\hline SN3 & 0.911 & 0.311505 & 0.325610 & 0.322041 & 0.123863 & $<0.05$ \\
\hline SN4 & 0.854 & 0.369727 & 0.366772 & 0.244643 & 0.199999 & $<0.05$ \\
\hline SN5 & 0.899 & 0.241902 & 0.386338 & 0.156360 & 0.100241 & $<0.05$ \\
\hline SM1 & 0.438018 & 0.854 & 0.697474 & 0.563594 & 0.089397 & $<0.05$ \\
\hline SM2 & 0.386663 & 0.835 & 0.617885 & 0.553755 & 0.063508 & $<0.05$ \\
\hline SM3 & 0.393276 & 0.841 & 0.558256 & 0.535703 & 0.213127 & $<0.05$ \\
\hline SM4 & 0.319932 & 0.810 & 0.528195 & 0.485191 & 0.009229 & $<0.05$ \\
\hline IG1 & 0.452838 & 0.657671 & 0.843 & 0.576769 & 0.085923 & $<0.05$ \\
\hline IG2 & 0.465280 & 0.566169 & 0.778 & 0.445699 & 0.154528 & $<0.05$ \\
\hline IG3 & 0.451126 & 0.494118 & 0.763 & 0.468638 & $0.002066-$ & $<0.05$ \\
\hline IP1 & 0.374344 & 0.607277 & 0.602436 & 0.900 & $0.018284-$ & $<0.05$ \\
\hline IP2 & 0.378768 & 0.592235 & 0.542839 & 0.896 & 0.036197 & $<0.05$ \\
\hline IP3 & 0.422830 & 0.530029 & 0.545906 & 0.901 & 0.149122 & $<0.05$ \\
\hline II1 & $0.02039-$ & 0.087872 & 0.022065 & 0.001023 & 0.864 & $<0.05$ \\
\hline II2 & $0.021975-$ & 0.120624 & 0.135820 & 0.108220 & 0.901 & $<0.05$ \\
\hline II3 & 0.039733 & 0.070582 & 0.098511 & 0.013832 & 0.793 & $<0.05$ \\
\hline
\end{tabular}

be analyzed in two levels. First, the measurement model is investigated through validity and reliability analyses and then structural model will be analyzed by determination coefficients, path estimation among variables and determining the fit index of the model.

\section{Results}

\subsection{Descriptive Data}

In this section, the demographic features of this statistical population, including gender, work experience, and expertise have been presented in Tab. 1.

\subsection{Confirmatory Factor Analysis} and Reliability and Validity Indicator

In Partial Least Squares, reliability of each indicator is determined by load factor. The value of load factor of each indicator should be equal or more than 0.5 (Fornell \& Larcker, 1981). Tab. 2 shows the results of confirmatory factor analysis and value of load factor of indicators. As it can be seen in Tab. 2, all of the amounts of indicators which are related to variables and have been shown in dark columns, are more than 0.5 . So it can be said that the measurement model has enough reliability in variables' indicators. Load factor in Tab. 2 have been also used to investigate the convergent validity of the indicators. To prove that variables' indicators have convergent validity, two criteria should be realized: first, the amounts of probability ( $p$-value) are less than 0.05 ; second, the related load factors are equal or more than 0.5. As it can be seen in Tab. 2, both expected criteria have been realized; therefore, variables' indicators have proper convergent validity. 


\section{Tab. 3: Cronbach's alpha for variables}

\begin{tabular}{l|c}
\multicolumn{1}{c|}{ Variable } & Cronbach's Alpha \\
\hline Social Network & 0.939 \\
\hline Sharing Mistakes & 0.855 \\
\hline Idea Generation & 0.708 \\
\hline Idea Promotion & 0.881 \\
\hline Idea Implementing & 0.824 \\
\hline
\end{tabular}

\subsection{Reliability of Constructs}

In most studies, to evaluate reliability of constructs, Cronbach's Alpha is used. As it can be seen in Tab. 3, the amounts of Cronbach's Alpha for all variables are more than 0.7 , so the measurement model has proper construct reliability.

\subsection{Convergent Validity of Constructs}

Convergent validity of constructs means that the collection of indicators determines the main construct. Fornell and Larcker (1981) suggested using Average Variance Extracted (AVE) for evaluating convergent validity. The least amount which is needed for enough convergent validity equals 0.5 ; and this will guarantee that at least $50 \%$ of variance of a construct is explained by indicators. Tab. 4 shows the AVE amounts for all variables and they are more than 0.5 which mean that convergent validity is proper.

\subsection{Structural Model Analysis and Hypothesis Testing}

The second level in Hulland (1999) approach is using determination coefficients, path analysis and model fit indexes in order to evaluate structural model.

The predicting strength of designed model, is analyzed by using the described variance amount $\left(R^{2}\right)$ for dependent variables (Chin, 1998). The analysis of determination coefficient will help understanding this fact that to what extent the variance of dependent variables is determinable by a collection of predictors (Sekaran, 2006). This coefficient indicates the change percentage of dependent variable which are imposed by independent variable. In this research, according to Tab. 5, it can be concluded that this research structural model has enough predicting strength. For example, about $64.5 \%$ of variance of "Idea Generation" variable has been described through the variables affecting this in that model, and its amount is an acceptable amount.

\section{Tab. 4: Convergent validity of constructs}

\begin{tabular}{l|l}
\multicolumn{1}{c|}{ Construct } & AVE \\
\hline Social Network & 0.811466 \\
\hline Sharing Mistakes & 0.697626 \\
\hline Idea Generation & 0.632487 \\
\hline Idea Promotion & 0.808098 \\
\hline Idea Implementing & 0.729329 \\
\hline
\end{tabular}




\begin{tabular}{l|c}
\multicolumn{1}{c|}{ Dependent Variable } & Determination Coefficient $\left.\mathbf{( R}^{2}\right)$ \\
\hline Sharing Mistakes & 0.215 \\
\hline Idea Generation & 0.645 \\
\hline Idea Promotion & 0.462 \\
\hline Idea Implementing & 0.020 \\
\hline
\end{tabular}

Generally, to investigate model fitness in researches which are based on PLS, CVCommunality (CV-Com) and CV-Redundancy (CV-Red) are used. In Fig. 2, the amounts of each index for dependent and independent variables have been shown. As it is seen, the indexes are positive and more than 0 , which shows good fitness of model. So regarding Fig. 2, it could be concluded that research model fits well and it is approved. In fact, these indexes evaluate the quality of conceptual model as suitable.

In order to identify the casual relationship between independent and dependent variables, path analysis has been used. Through using PLS algorithms, path analysis has been analyzed. The results of structural equations model and the amount of $t$ statistics through which the significance of path coefficients are investigated can be seen in Tab. 6. In this level, research hypotheses will be tested through using path coefficients and their level of significance. The amount of $t$ statistics shows the significance of path coefficient, and if its amount is higher than 1.96, it means that this coefficient is significant in error level of 0.05 . Otherwise, path coefficient is not significant and the hypothesis is refused (Fornell \& Larcker, 1981). The results of testing direct path have been shown in Tab. 6 .

After investigating the existing relationship in direct path among variables in the mentioned hypotheses and being significant or not significant has been determined; it becomes

\section{Fig. 2: Research model fit indexes}

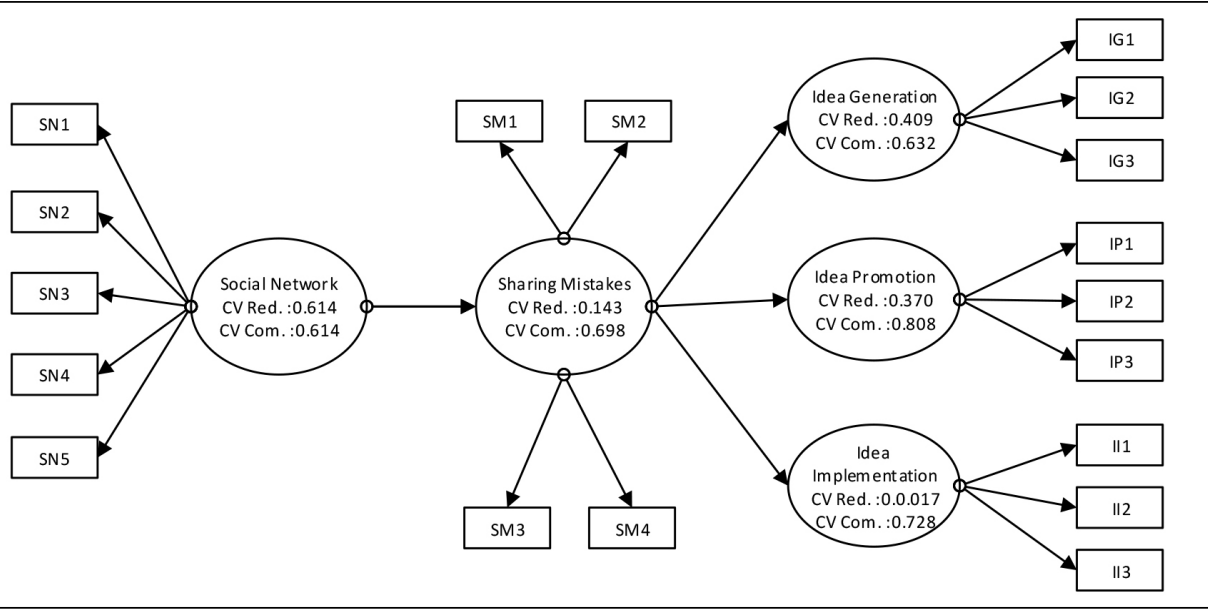




\section{Informační management}

\section{Tab. 6: The results of testing direct path}

\begin{tabular}{l|c|c|c|c}
\multicolumn{1}{c|}{ Direct Path } & $\begin{array}{c}\text { Path } \\
\text { Coefficient }\end{array}$ & $\begin{array}{c}\text { Significance } \\
\text { Number }\end{array}$ & Test Result & $\begin{array}{c}\text { Approval/Refusal } \\
\text { of Hypothesis }\end{array}$ \\
\hline Social network $\rightarrow$ Sharing mistakes & 0.464 & 5.349 & Significant & Approval \\
\hline Sharing mistakes $\rightarrow$ Idea generation & 0.386 & 4.092 & Significant & Approval \\
\hline Sharing mistakes $\rightarrow$ Idea promotion & 0.417 & 4.069 & Significant & Approval \\
\hline Sharing mistakes $\rightarrow$ Idea Implementation & 0.120 & 0.708 & Not Significant & Refusal \\
\hline Social network $\rightarrow$ Idea generation & 0.105 & 1.145 & Not Significant & Refusal \\
\hline Social network $\rightarrow$ Idea promotion & 0.205 & 2.602 & Significant & Approval \\
\hline Social network $\rightarrow$ Idea implementation & 0.097 & 0.781 & Not Significant & Refusal \\
\hline
\end{tabular}

Source: own

\section{Tab. 7: The results of testing indirect path}

\begin{tabular}{l|c|c}
\multicolumn{1}{c|}{ Indirect Path } & Test Result & Approval/Refusal \\
\hline Social network $\rightarrow$ sharing mistakes $\rightarrow$ idea generation & Significant & Approval \\
\hline Social network $\rightarrow$ sharing mistakes $\rightarrow$ idea promotion & Significant & Approval \\
\hline Social network $\rightarrow$ sharing mistakes $\rightarrow$ idea implementation & Not Significant & Refusal \\
\hline
\end{tabular}

Source: own

\section{Fig. 3: The final result of research model}

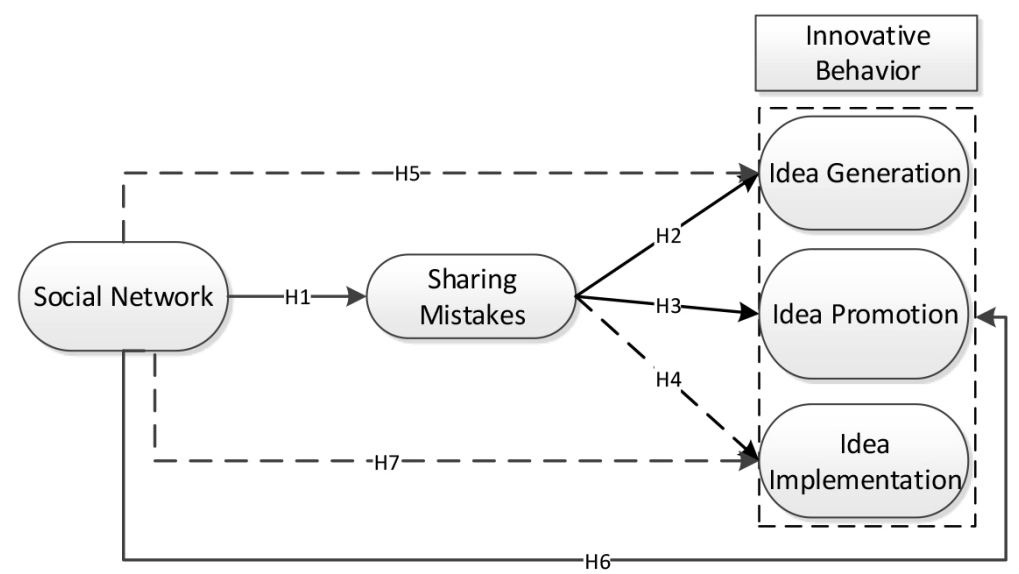


possible to discuss the hypotheses which are related to mediatory variable. If $t$ statistics between independent and mediatory variable and also between mediatory and dependent variable is higher than 1.96 , it can be concluded that these two coefficients are significant in the error level of 0.05 ; it means that there is a significant relationship between independent and dependent variable through mediatory variable. The results of testing indirect path have been brought in Tab. 7 .

After investigating research hypotheses, a general conclusion can be reached about research model. Considering Tabs. 5 and 6 , final model of this research can be presented like Fig. 3. It should be mentioned that if a relation is not significant and the hypothesis related to it is refused, it should be shown through dashed line.

\section{Discussion}

In this section, in addition to a brief review over approval or refusal of research hypotheses (its related results have been shown in section 3 ), these results will be analyzed deeply.

Hypothesis 1 states that social network has a positive impact on sharing mistakes among IT professionals. According to research findings, path coefficient between these two constructs is 0.464 and $t$ statistics equals 5.349 , which is higher than 1.96. As a result, it can be said that social network has a positive and significant impact on sharing mistakes. The research result for hypothesis 1 is in line with previous studies. For example, Borges (2012) believes that a strong social network among IT professionals can have positive and significant effects on sharing knowledge which includes work mistakes as well. One of the reasons of this issue can be this: the existence of a strong social network among IT professionals can make their friendly relationship more strong, and in this friendly and close atmosphere, they can state and share their mistakes easier.

Hypothesis 2 states that sharing mistakes has positive impact on idea generation among IT professionals. According to research findings, path coefficient between these two constructs is 0.386 and t statistics equals 4.092 which is higher than 1.96 . So it can be said that sharing mistakes affects idea generation positively and significantly. Hypothesis 3 says that sharing mistakes has positive effect on idea promotion among IT professionals.
According to the derived results, path coefficient between these two constructs is 0.386 and t statistics equals 4.069 which is higher than 1.96. Therefore, it can be stated that sharing mistakes affects idea promotion positively and significantly. Hypothesis 4 states that sharing mistakes affects idea implementation among IT professionals positively. Regarding research results, path coefficient between the two constructs is 0.120 and t statistics equals 0.708 which is lower than 1.96. So sharing mistakes does not have positive and significant impact on idea implementation, and the hypothesis is refused.

The research results for hypotheses 2 and 3 are in line with previous studies; for example, the results of Mura et al. (2013) show that sharing mistakes affects innovative behavior of the employees; it means that sharing mistakes provoke more efforts to generate and promote new ideas. when an IT professional shares his mistakes that he has reached during the years, with his colleagues; his colleagues also dare to share their mistakes as well. In this way, the mentioned person can reach creative ideas through using others 'knowledge and experiences and learning from work mistakes. In other word, this person acquires innovative behavior in the aspect of idea generation. Moreover, the atmosphere which has been created by sharing mistakes and experiences is trustworthy and friendly enough that invite people to share their ideas with managers and co-workers; or in other words, it helps people to have innovative behavior in the aspect of idea promotion. Sharing work mistakes lets the employees share and discuss their ideas with managers and colleagues, and try to attract their attention to advantages of ideas. The results of testing hypothesis 4 shows that sharing mistakes has no positive and significant impact on idea implementation. Because implementing idea and performing innovation, need necessities and conditions far beyond sharing mistakes.

Hypothesis 5 states that social network has positive impact on idea generation among IT professionals. According to research findings, path coefficient between two construct is 0.105 and $t$ statistics also equals 1.145 which is lower than 1.96. So social network does not affect idea generation positively and significantly, and the hypothesis is refused. Hypothesis 6 says that social network has positive impact on idea 
promotion among IT professionals. Based on research results, path coefficient between the two constructs is 0.205 and t statistics equals 2.602 which is higher than 1.96. Therefore, social network affects idea promotion positively and significantly. Hypothesis 7 states that social network affects implementing ideas positively among IT professionals. Regarding research results, path coefficient between the two constructs is -0.097 and t statistics equals 0.781 which is lower than 1.96. As a result, social network does not have positive and significant impact on idea implementation, so the hypothesis is refused.

The findings of this research have shown that IT professionals who are in contact with each other in a social network and they have friendly and close relationships; have innovative behavior in the aspect of idea promotion (hypothesis 6). Because IT professionals seek for protection and support of other colleagues from their innovative idea in a friendly atmosphere and strong social network; for their innovative ideas they try to have the necessary attention and approval of their co-workers, and they encourage the important member of their organization to pay attention to their innovative ideas. Regarding hypothesis 6 approval and hypotheses 5 and 7 refusal, it can be said that social network has positive and significant impact on idea promotion among the three aspects of innovative behavior; because IT professionals who create a social network with their colleagues, discuss their ideas with each other more conveniently because they have friendly relationship. But social network has no impact on idea generation (hypothesis 5) and idea implementation (hypothesis 7 ). The reason could be that generating and implementing ideas in comparison with promoting ideas need conditions and necessities far beyond social network of the employees, and in the next three hypotheses, these necessities have been discussed.

Hypothesis 8 states that sharing mistakes mediates the relationship between social network and idea generation among IT professionals. In the first part of the path, the research's first hypothesis which is social network has positive and significant impact on sharing mistakes has been approved. In the second half of the path, the second hypothesis which states the positive and significant relationship between sharing mistakes and idea generation, has been tested in error level of $5 \%$ and has been approved. When both parts of indirect path with the mediatory role of sharing mistakes are significant, it can be concluded that sharing mistakes has a mediatory role between social network and idea generation, and its mediatory degree is 0.179 ; so hypothesis 8 is also approved.

Hypothesis 9 says that sharing mistakes mediates the relationship between social network and idea promotion among IT professionals. In the first part of the path, the research's first hypothesis which is social network has positive and significant impact on sharing mistakes has been approved. In the second half of the path, the third hypothesis which states the positive and significant relationship between sharing mistakes and idea promotion, has been tested in error level of $5 \%$ and has been approved. When both parts of indirect path with the mediatory role of sharing mistakes are significant, it can be concluded that sharing mistakes has a mediatory role between social network and idea promotion, and its mediatory degree is 0.193 ; so hypothesis 9 is also approved.

Hypothesis 10 says that sharing mistakes mediates the relationship between social network and idea implementation among IT professionals. In the first part of the path, the research's first hypothesis which is social network has positive and significant impact on sharing mistakes has been approved. In the second half of the path, the forth hypothesis which states that the positive and significant relationship between sharing mistakes and idea implementation has been refused. So it can be concluded that sharing mistakes does not have a mediatory role between social network and idea implementation; so hypothesis 10 is refused.

The findings of this research have shown that the existence of a social network among IT professionals is effective on idea generation and promotion when the professionals in this network share their mistakes together (hypotheses 8 and 9). Because on one hand, when employees know about the mistakes of their colleagues, they try to create more and better ideas to avoid remaking them. And they share these ideas more than before. On the other hand, when employees make a friendly social network with each other, it is more possible that they share their work mistakes 
together, because those employees who have social network are friendly and close. Because of this, they are willing to talk about work with their colleagues and during these talks gaps, knowledge and experiences which have been gained through mistakes will be shared.

\section{Conclusion}

This research aims at exploring the effects of social network on the innovative behavior of IT professionals through the mediating role of sharing mistakes. The dependent variable in this research is the innovative behavior. The reason for considering this variable is that in today's business world, being so competitive, innovation can be a competitive advantage for the companies. Without having competitive advantages, the companies are not able to survive the competitive market. The importance of innovation for IT companies is double, because of the high pace of change and the intensity of competition in this industry. To be innovative, the companies require innovative employees, since innovation depends on humans and it is only the innovative employees who can add innovation to their companies. For the realization of an innovation, the ideas coming to the mind of employees should not be blocked at this stage, yet they should attract their managers' and colleagues' support and collaboration and implement it with their help. In other words, for the realization of an innovation, the employees should show three kinds of behavior: idea generation, idea promotion, and idea implementation, constituting innovative behavior.

The mediator variable in this research is sharing mistakes, which is one of the dimensions of knowledge sharing. The employees face mistakes while doing their tasks, which are an inevitable part of the organizational activities (Homsma et al., 2009). The mistakes that provide the employees with new knowledge are considered as smart errors and have desired results for the organizations (Edmondson, 2011). From Madsen and Desai's (2010) point of view, the knowledge gained from the organizational mistakes in comparison with the knowledge that is gained from a success, is more effective on the improvement of the organization's performance. The main achievement of this research is the exploration of the role of sharing mistakes as mediator, since in previous researches, when the knowledge sharing is discussed, mostly, sharing the best practices have been dealt with and sharing the mistakes has been rarely discussed.

Hypothesis 1 states that social network has a positive impact on sharing mistakes among IT professionals. Because when an employee, in social network, shares his mistakes that he has reached during the years, with his colleagues; his colleagues also dare to share their mistakes as well. According to Dyck (2000), free communication within the organization about the work mistakes results in sharing the experience and knowledge amongst the members of the organization. The social network of the employees is a place where there is a free communication among the members. The friendly atmosphere of the social network lets the people to be more comfortable and share their work mistakes easily and without the fear of being mocked and embarrassed or left out. They are sure that in this circle of friends in the social network, their mistakes will not be revealed to others.

Hypothesis 2 and 3 state that sharing mistakes has a positive impact on the idea generation and idea promotion among the IT professionals. It means that sharing mistakes provoke more efforts to generate and promote new ideas. In the other words one can reach creative ideas through using others' knowledge and experiences and learning from work mistakes. Moreover, the atmosphere which has been created by sharing mistakes and experiences is trustworthy and friendly enough and invites people to share their ideas with managers and co-workers and try to attract their attention to the advantages of ideas. It should be noted, sharing mistakes is a better stimulator for innovation, in comparison to sharing the best practices, since when the best practices are shared, the mind is blocked and the innovational ideas are prevented. Yet, when the mistakes are shared, the employees try to cover the gap, resulting from mistakes, through proposing ideas and prevent the reoccurrence of these mistakes in the future, through producing new ideas. Because of refusing hypothesis 4 , sharing mistakes does not have positive and significant impact on idea implementation. The reason could be that in order to implement the idea, the best practices are more needed than the work mistakes. Because the best practices provide the employees a defined way to implement an idea. 
The independent variable in this research is social network. The reason behind considering this variable is that various factors are influential in innovative behavior. Through identifying these factors and working on them, one can improve the employees' innovative behavior. The previous research has referred to different factors, yet one of the factors, which has been explored less than others but has so many effects on the innovative behavior, is the social network. One of the scientific achievements of this research is the exploration of the effects of social network on innovative behavior, which rarely has been the focus of previous researches. Hypothesis 6 in this study says that social network has positive impact on idea promotion. But because of refusing hypothesis 5 and 7 , social network does not have positive and significant impact on idea generation and implementation. This findings have shown that IT professionals who have contacts with each other in social network, and they are so sincere out of workplace that they talk about their Personal issues together, help each other in solving their personal problems, and in case of achieving any success, celebrate it together; have innovative behavior in the aspect of idea promotion. Because IT professionals seek for protection and support of other colleagues from their innovative idea in a friendly atmosphere and strong social network and they try to have the necessary attention and approval of their coworkers. The interesting aspect about the social networks is that although they have an impact on developing ideas, they have no impact on implementing and producing those ideas. The reason could be that promoting ideas needs more social cooperation than generating and implementing the ideas.

Furthermore, if one wants to enhance the effects of the employees' social network on their innovative behavior, the social network should provide more options to enhance their inclination towards sharing their work mistakes; and this is possible, since the employees who have contact with each other through social network, are willing to share their mistakes with the other employees, make use of their ideas and opinions to compensate for those mistakes and prevent their reoccurrence. Hypothesis 8 states that sharing mistakes mediates the relationship between social network and idea generation and promotion among IT professionals. The social network among employees is effective on idea generation and promotion when the employees in this network share their mistakes together. Because, when employees know about the mistakes of their colleagues, they try to create more and better ideas to avoid remaking them; and they share these ideas more than before. Also when employees make a friendly social network with each other, it is more possible that they share their work mistakes together, because those employees who have social network are friendly and close. Because of this, they are willing to talk about work with their colleagues and during these talks gaps, knowledge and experiences which have been gained through mistakes will be shared.

The interesting fact about the social networks is that without the mediating role of sharing work mistakes, they have no impact on generating ideas. Whereas, by being a mediator of sharing mistakes, the social networks have an impact on generating ideas. The reason for this could be that without sharing mistakes, the atmosphere of the social networks does not help the IT professional to derive ideas from them. But when the work mistakes are shared, the employees will try to prevent them by generating ideas and being innovative. Because of refusing hypothesis 10 sharing mistakes does not have a mediatory role between social network and idea implementation, because in order to implement the idea, the best practices are more needed than the mistakes.

About Implications for Practice, according to hypotheses 2 and 3 , in order to develop innovative behavior in IT professionals, an atmosphere should be created in the company in which these people can share their experience and knowledge from their past mistakes with each other. The managers of these companies can develop innovative behavior and idea generation and promotion through improving sharing mistakes among IT professionals. Considering the importance of sharing mistakes in developing innovative behavior of IT professionals, and according to Hypothesis 1 it is suggested to create and strengthen a social network among IT employees to improve and promote sharing mistakes; because those employees who make a friendly social network with each other, share their mistakes more willingly and conveniently. Also based on hypotheses 8 and 9 , sharing mistakes has a mediatory role in the relationship between social network 
and idea generation and promotion. So, if a company wants its human workforce to have innovative behavior, generate ideas and also share their ideas with each other, it should facilitate the creation of social network among the employees; then in these networks, sharing mistakes will happen, and in this atmosphere the employees share their knowledge which they have learned from the past mistakes with their colleagues.

About Implications for Research, this study has investigated the impact of social network on innovative behavior of IT professionals with the mediatory role of sharing mistakes. In this field, it is recommended that researchers consider the mediatory impact of other variables such as creating knowledge and implementing knowledge on the relationship between social network and innovative behavior, because creating knowledge will provide the proper foundation for generating new ideas. In addition, implementing knowledge will help idea promotion and idea implementation.

Finally it should be noted that although the social network of employees is effective on sharing mistakes and innovative behavior, it carries some risks too. One of them is that in social networks people trust each other and share their ideas but there might be some people who misuse the trust and introduce the ideas under their own names (Martin, Rao, \& Sloan, 2009). Another risk that might happen is that when an employee leaves the network, his shared work mistakes might be used against him (lowinski, Hummel, \& Kumpf, 2006). So, the issue would be how to convince the employees to use the social network. It seems that there are some options for this purpose but certainly it is not easy. One of the important ways is to convince the employees that the company guarantee the keeping of knowledge and do not permit anyone to use this knowledge against others. In other words, the company should try to improve its culture of accepting the risk of mistake so that the employees feel free to explain their mistakes (Van Dyck, Frese, Baer, \& Sonnentag, 2005).

\section{References}

Borges, R. (2012). Tacit knowledge sharing between IT workers: The role of organizational culture, personality, and social environment. Management Research Review, 36(1), 89-108. https://doi.org/10.1108/01409171311284602.
Bouman, A. (2010). 21 Tech Companies that Changed The World... Before They Died. Retrieved from: http://www.maximumpc. com/21-tech-companies-that-changed-theworld-before-they-died/\#.

Bowers, J., \& Khorakian, A. (2014). Integrating risk management in the innovation project. European journal of innovation management, 17(1), 25-40. https://doi. org/10.1108/EJIM-01-2013-0010.

Brass, D. J. (2003). A social network perspective on human resources management. In Networks in the knowledge economy (pp. 283-323).

Burt, R. S. (2004). Structural holes and good ideas1. American journal of sociology, 110(2), 349-399. https://doi.org/10.1086/421787.

Cannon, M. D., \& Edmondson, A. C. (2001). Confronting failure: Antecedents and consequences of shared beliefs about failure in organizational work groups. Journal of organizational behavior, 22(2), 161-177. https://doi.org/10.1002/job.85.

Chen, I. Y., \& Chen, N.-S. (2009). Examining the factors influencing participants' knowledge sharing behavior in virtual learning communities. Educational Technology \& Society, 12(1), 134-148.

Chin, W. W. (1998). The partial least squares approach to structural equation modeling. Modern methods for business research, 295(2), 295-336.

Constantinides, P.(2013). The communicative constitution of IT innovation. Information and Organization, 23(4), 215-232. https://doi. org/10.1016/j.infoandorg.2013.07.002.

De Spiegelaere, S., Van Gyes, G., De Witte, H., Niesen, W., \& Van Hootegem, G. (2014). On the relation of job insecurity, job autonomy, innovative work behaviour and the mediating effect of work engagement. Creativity and innovation management, 23(3), 318-330. https://doi.org/10.1111/caim.12079.

Edmondson, A. C. (2011). Strategies for learning from failure. Harvard Business Review, 89(4), 48-55.

Fornell, C., \& Larcker, D. F. (1981). Evaluating structural equation models with unobservable variables and measurement error. Journal of marketing research, 18(1), 39-50. https://doi.org/10.2307/3151312.

Hansen, M. T., Mors, M. L., \& Løvås, B. (2005). Knowledge sharing in organizations: Multiple networks, multiple phases. Academy 
of management journal, 48(5), 776-793. https://doi.org/10.5465/AMJ.2005.18803922.

Homsma, G. J., Van Dyck, C., De Gilder, D., Koopman, P. L., \& Elfring, T. (2009). Learning from error: The influence of error incident characteristics. Journal of Business Research, 62(1), 115-122. https://doi.org/10.1016/j. jbusres.2007.12.003.

Hulland, J. (1999). Use of partial least squares (PLS) in strategic management research:Areview of four recent studies. Strategic Management Journal, 20(2), 195-204. https://doi.org/10.1002/ (SICI)1097-0266(199902)20:2<195::AIDSMJ13>3.0.CO;2-7.

Hülsheger, U. R., Anderson, N., \& Salgado, J. F. (2009). Team-level predictors of innovation at work: a comprehensive meta-analysis spanning three decades of research. Journal of applied psychology, 94(5), 1128. https://doi. org/10.1037/a0015978.

Janssen, O. (2000). Job demands, perceptions of effort-reward fairness and innovativeworkbehaviour. Journalofoccupational and organizational psychology, 73(3), 287-302. https://doi.org/10.1348/096317900167038.

Janssen, O. (2004). How fairness perceptions make innovative behavior more or less stressful. Journal of organizational behavior, 25, 201-215. https://doi.org/10.1002/job.238.

Kanter, R., \& Myers, P. (1996). When a thousand flowers bloom: structural, collective, and social conditions for innovation in organizations. In P. S. Myers (Ed.), Knowledge Management and Organisational Design (pp. 93-131). Boston: Butterworth-Heinemann.

Madsen, P. M., \& Desai, V. (2010). Failing to learn? The effects of failure and success on organizational learning in the global orbital launch vehicle industry. Academy of Management Journal, 53(3), 451-476. https://doi.org/10.5465/amj.2010.51467631.

Martin, D. E., Rao, A., \& Sloan, L. R. (2009). Plagiarism, integrity, and workplace deviance: Acriterion study. Ethics \& Behavior, 19(1), 36-50. https://doi.org/10.1080/10508420802623666.

Montes, F. J. L., Moreno, A. R., \& Fernández, L. M. M. (2004). Assessing the organizational climate and contractual relationship for perceptions of support for innovation. International Journal of Manpower, 25(2), 167-180. https://doi. org/10.1108/01437720410535972.

Mura, M., Lettieri, E., Radaelli, G., \& Spiller, N. (2013). Promoting professionals' innovative behaviour through knowledge sharing: the moderating role of social capital. Journal of Knowledge Management, 17(4), 527-544. https://doi.org/10.1108/JKM-03-2013-0105.

Nonaka, I. (1994). A dynamic theory of organizational knowledge creation. Organization science, 5(1), 14-37. https://doi. org/10.1287/orsc.5.1.14.

Palmer, M. A. (2010). The role of attitudes, individual innovativeness, and organizational support for innovation in evidence-based practice implementation. University of South Dakota.

Perry-Smith, J. E., \& Shalley, C. E. (2003). The social side of creativity: A static and dynamic social network perspective. Academy of management review, 28(1), 89-106. https://doi.org/10.5465/AMR.2003.8925236.

Phelps, C., Heidl, R., \& Wadhwa, A. (2012). Knowledge, networks, and knowledge networks a review and research agenda. Journal of management, 38(4), 1115-1166. https://doi. org/10.1177/0149206311432640.

Radaelli, G., Mura, M., Spiller, N., \& Lettieri, E. (2011). Intellectual capital and knowledge sharing: the mediating role of organisational knowledge-sharing climate. Knowledge Management Research \& Practice, 9(4), 342-352. https://doi.org/10.1057/kmrp.2011.29.

Reagans, R., \& McEvily, B. (2003). Network structure and knowledge transfer: The effects of cohesion and range. Administrative science quarterly, 48(2), 240-267. https://doi. org/10.2307/3556658.

Scott, S. G., \& Bruce, R. A. (1994). Determinants of innovative behavior: A path model of individual innovation in the workplace. Academy of management journal, 37(3), 580607. https://doi.org/10.2307/256701.

Sekaran, U. (2006). Research methods for business: A skill building approach. John Wiley \& Sons.

Slowinski, G., Hummel, E., \& Kumpf, R. J. (2006). Protecting know-how and trade secrets in collaborative R\&D relationships. ResearchTechnology Management, 49(4), 30-38. https://doi.org/10.1080/08956308.2006.11657385.

Small, C. T., \& Sage, A. P. (2006). Knowledge management and knowledge sharing: A review. Information, Knowledge, Systems Management, 5(3), 153-169.

Szabo, Z. K., Soltés, M., \& Herman, E. (2013). Innovative capacity \& performance of transition economies: Comparative study 
at the level of enterprises. E\&M Ekonomie a Management, 16(1), 52-68.

Taştan, S. B. (2013). The influences of participative organizational climate and selfleadership on innovative behavior and the roles of job involvement and proactive personality: A survey in the Context of SMEs in Izmir. Procedia-Social and Behavioral Sciences, 75, 407-419. https://doi.org/10.1016/j. sbspro.2013.04.045.

Teigland, R., Di Gangi, P. M., Flåten, B.-T., Giovacchini, E., \& Pastorino, N. (2014). Balancing on a tightrope: Managing the boundaries of a firm-sponsored OSS community and its impact on innovation and absorptive capacity. Information and Organization, 24(1), 25-47. https://doi.org/10.1016/j. infoandorg.2014.01.001.

Tortoriello, M., Reagans, R., \& McEvily, B. (2012). Bridging the knowledge gap: The influence of strong ties, network cohesion, and network range on the transfer of knowledge between organizational units. Organization science, 23(4), 1024-1039. https://doi. org/10.1287/orsc.1110.0688.

Van Dyck, C. (2005). Putting errors to good use: Error management culture in organizations (doctoral dissertation, Faculty of Social and Behavioural Sciences. University of Amsterdam).

Van Dyck, C., Frese, M., Baer, M., \& Sonnentag, S. (2005). Organizational error management culture and its impact on performance: a two-study replication. Journal of applied psychology, 90(6), 1228-1240. https://doi.org/10.1037/0021-9010.90.6.1228.
Wang, X. H. F., Fang, Y., Qureshi, I., \& Janssen, O. (2015). Understanding employee innovative behavior: Integrating the social network and leader-member exchange perspectives. Journal of organizational behavior, 36(3), 403-420. https://doi. org/10.1002/job.1994.

Wong, S.-S., \& Boh, W. F. (2010). Leveraging the ties of others to build a reputation for trustworthiness among peers. Academy of management journal, 53(1), 129-148. https://doi.org/10.5465/AMJ.2010.48037265.

Woodman, R. W., Sawyer, J. E., \& Griffin, R. W. (1993). Toward a theory of organizational creativity. Academy of management review, 18(2), 293-321. https://doi.org/10.5465/ AMR.1993.3997517.

Assist. Prof. Alireza Khorakian, Ph.D. Ferdowsi University of Mashhad (FUM) Faculty of Economic and Administrative Sciences Department of Management Iran a.khorakian@um.ac.ir and

Stirling Management School (Honorary lecturer) University of Stirling United Kingdom alireza.khorakian@stir.ac.uk

Mostafa Jahangir, Ph.D. student Ferdowsi University of Mashhad (FUM) Faculty of Economic and Administrative Sciences Department of Management Iran mjahangir@stu.um.ac.ir 


\title{
Abstract
}

\section{THE IMPACT OF SOCIAL NETWORK ON THE INNOVATIVE BEHAVIOR OF IT PROFESSIONALS: WHAT IS THE ROLE OF SHARING MISTAKES?}

\author{
Alireza Khorakian, Mostafa Jahangir
}

In today's competitive world, organizations need constant innovations in products, services and processes in order to grow and survive. Key of Innovation is in the innovative behavior of organization employees. Various factors affect the innovative behavior of the staff. The existence of a social network among the employees is one of the factors which can affect this behavior. Despite this fact, the way it affects is one of the major issues in the society of IT professionals. The aim of the research is investigating the mediatory role of sharing mistakes in the impact of social network on innovative behavior of IT professionals. In order to evaluate the research variables, a questionnaire of 18 questions has been used. This questionnaire has been distributed among 210 IT professionals in Mashhad. To analyze the data, structural equation modeling has been used. The results of this research showed that social network has positive impact on sharing mistakes. Also sharing mistakes has impact on generating and promoting ideas. In addition sharing mistakes mediates the impact of social network on generating and promoting ideas. Finally, in the conclusion of the scientific achievement of this research, one can refer to the fact that to promote and develop the IT companies in this competitive industry, innovation is needed. Innovation is created by the innovative employees. To behave innovatively, the employees should have contact through social network, yet if the social network leads the employees to share their mistakes, it would enhance the innovative behavior to a greater extent.

Key Words: Sharing mistakes, innovative behavior, social network, IT professionals.

JEL Classification: O31, M10, D83.

DOI: 10.15240/tul/001/2018-3-012 